\title{
DESEMPENHO AGRONÔMICO DA ABÓBORA HÍBRIDA POLINIZADA COM DIFERENTES DOSES DE FITORREGULADORES NA REGIÃO OESTE DA BAHIA
}

\author{
Naiane de Macedo Oliveira ${ }^{1}$; Loanny de Souza Santos ${ }^{2}$; Lucas Miguel Carvalho da Silva ${ }^{3}$; \\ Marilucia de Jesus Gomes ${ }^{4}$; Alberto do Nascimento Silva ${ }^{5}$
}

DOI: https://doi.org/10.31692/978-65-991061-4-9.106-110

\section{INTRODUÇÃO}

As olerícolas são plantas cultivadas em todas as regiões do Brasil, especialmente no Nordeste, onde apresenta boas condições de solo e clima favoráveis ao crescimento e desenvolvimento dessas espécies. Neste meio, destaca-se a família das cucurbitáceas, como a abóbora, que nessa região é considerada como uma cultura de subsistência (DO CARMO et al., 2011).

Dentre as espécies de abóboras cultivadas, evidencia-se a abóbora híbrida Tetsukabuto, também conhecida como abóbora japonesa ou kabutiá que é derivada do cruzamento entre linhagens selecionadas de moranga Curcubita máxima e linhagens de abóbora Curcubita moschata, no qual houve a junção das boas características das duas espécies em uma só espécie. (AMARO, 2014).

Apesar da abóbora híbrida Tetsukabuto obter expressão sexual monoica, ou seja, produz flores femininas e masculinas na mesma planta, são considerados machos estéreis, pois a maturação das flores masculinas e femininas ocorre em períodos diferentes. Assim para contornar as falhas no processo de polinização e qualidades dos frutos é necessário o plantio sincronizado de outras abóboras ou morangas que auxiliarão no fornecimento de pólen para a polinização cruzada entomófila ou mesmo o uso de mecanismos indutores de partenocarpia via aplicação de reguladores de crescimento. (AMARO, 2014)

Tendo em vista estes problemas a solução viável seria utilizar reguladores de crescimento, encontrado no hormônio vegetal conhecido como auxina. Utilizando o método de partenocarpia, é possível obter o fruto sem recorrer a polinização natural, pois a pulverização é realizada na flor aberta, diretamente sobre o pistilo (KRISHNAMOORTHY, 1981; WITTWER, 1983).

Todavia na literatura não dispõe de informações suficientes acerca da aplicação de

\footnotetext{
${ }^{1}$ Graduando em Engenharia Agronômica, Universidade do Estado da Bahia - UNEB, macedonay80@ gmail.com

2 Graduando em Engenharia Agronômica, Universidade do Estado da Bahia - UNEB, loanny.ssantos@gmail.com

3 Graduando em Engenharia Agronômica, Universidade do Estado da Bahia UNEB,lucas_jmiguel@hotmail.com

${ }^{4}$ Graduando em Engenharia Agronômica, Universidade do Estado da Bahia - UNEB, mariluciamjg@gmail.com

${ }^{5}$ Mestre em Agronomia, Universidade do Estado da Bahia, albnsilva@uneb.br
} 
doses de 2,4-D em flores femininas de abóbora (PEREIRA, 2012). No Oeste da Bahia o cenário não se difere, são poucas as informações a respeito e é baixo o número de produtores que utiliza essa tecnologia de produção. Consequentemente, o presente trabalho tem como objetivo, avaliar o desempenho agronômico da abóbora hibrida Tetsukabuto polinizada com diferentes doses do fitorregulador 2,4 -D.

\section{FUNDAMENTAÇÃOTEÓRICA}

\section{Aspectos gerais do cultivo da abóbora tetsukabuto}

A abóbora híbrida Tetsukabuto é de expressão sexual monoica produz flores femininas e masculinas na mesma planta. Entretanto, por apresentarem uma taxa ou nula de abertura das flores masculinas, essas são consideradas machos estéreis, sendo assim é necessário o plantio sincronizado de outras abóboras ou morangas para frutificação da planta, por meio do fornecimento de pólen para a polinização cruzada entomófila ou mesmo o uso de técnicas indutoras de partenocarpia via aplicação de reguladores de crescimento. (Cheng; Gavilanes, 1980; Pereira, 1999; Amaro et al., 2014)

\section{Importância dos fitorreguladores na frutificação das abóboras}

A frutificação assexuada é feita através da aplicação externa de um fitohormônio com característica da auxina. A formação de frutos partenocárpicos é possível via aplicação externa de um hormônio sintético (ácido indol acético, alfa naftaleno acetato de sódio) ou produto com efeitos semelhantes da auxina, tal como o 2,4-D (ácido 2,4diclorofenoxiacético). Dessa forma, promovem o crescimento, principalmente pela elongação de células, quando aplicadas em concentrações de $10^{9}$ Molar, aproximadamente. (AMARO, 2014).

Durante as aplicações diárias deve-se evitar o escorrimento da solução nas ramas e folhas. Isto porque plantas de abóbora híbrida não toleram concentrações maiores que $0,4 \mathrm{a}$ 0,5 mg do ingrediente ativo do 2,4-D. Essa aplicação da substância reguladora de crescimento deve ser feita no período matutino (6:00 às 11:00h) quando as flores estão abertas e receptivas à fecundação, durante toda a fase de florescimento, e na dosagem correta, pois o 2,4-D aplicado em concentrações altas atua de maneira inversa à auxina natural existente no interior das plantas, causando uma desregulação nos principais processos metabólicos da planta. (AMARO,2014).

\section{METODOLOGIA}

A natureza da pesquisa constitui do tipo quantitativa experimental. Dessa forma o [107] 
experimento foi conduzido na Fazenda Modelo Paulo Mizote, em Barreiras, BA, Brasil (latitude $12^{\circ} 05^{\prime} 17.7^{\prime}$ S S, longitude $44^{\circ} 55^{\prime} 16.7^{\prime}$ 'W) no período de maio a agosto de 2019 . A região encontra-se no bioma Cerrado e o clima, segundo Köppen e Geiger é classificado como Aw e o solo da área experimental é identificado como ARGISSOLO VERMELHO. Foi utilizado o delineamento de blocos ao acaso com seis tratamentos e cinco repetições, totalizando 30 unidades experimentais. Os tratamentos foram compostos por: T0 - controle (0 $\mathrm{mL}$ de 2,4-D); T1 - 0,1 mL de 2,4-D; T2 - 0,2 mL de 2,4-D; T3 - 0,3 mL de 2,4-D; T4 - 0,4 $\mathrm{mL}$ de 2,4-D; T5 - 0,5 mL de 2,4-D. Cada parcela foi composta por três plantas com espaçamento de $2,5 \mathrm{~m}$ entre plantas e $2 \mathrm{~m}$ entre linhas.

A semeadura ocorreu início do mês de maio, em covas previamente adubadas, com recomendação feita de acordo com análise de solo. Foram utilizadas duas sementes por cova. Aos 20 dias de emergência (DAE) foi realizado o desbaste, deixando apenas uma planta por cova. A variedade utilizada foi Abóbora Híbrida Tetsukabuto F1.

No surgimento das primeiras flores, iniciou-se o processo de polinização artificial no período matinal.

Aos 93 dias, após a semeadura realizou-se a colheita, onde procedeu-se a avaliação da eficiência do fitorregulador no desenvolvimento dos frutos, analisando as seguintes variáveis: número de frutos por planta e peso médio dos frutos. Os dados obtidos foram submetidos a análise de variância pelo teste F, para efeito de doses de 2,4-D foram ajustadas equações de regressão para que melhor representassem os valores observados. As análises foram feitas com auxílio do software SISVAR.

\section{RESULTADOS E DISCUSSÃO}

Na figura 1, estão apresentados os valores da variável, números de frutos por planta.

Figura 1: Número de frutos por planta da abóbora híbrida Tetsukabuto, em função de doses de 2,4-D, na região Oeste da Bahia.

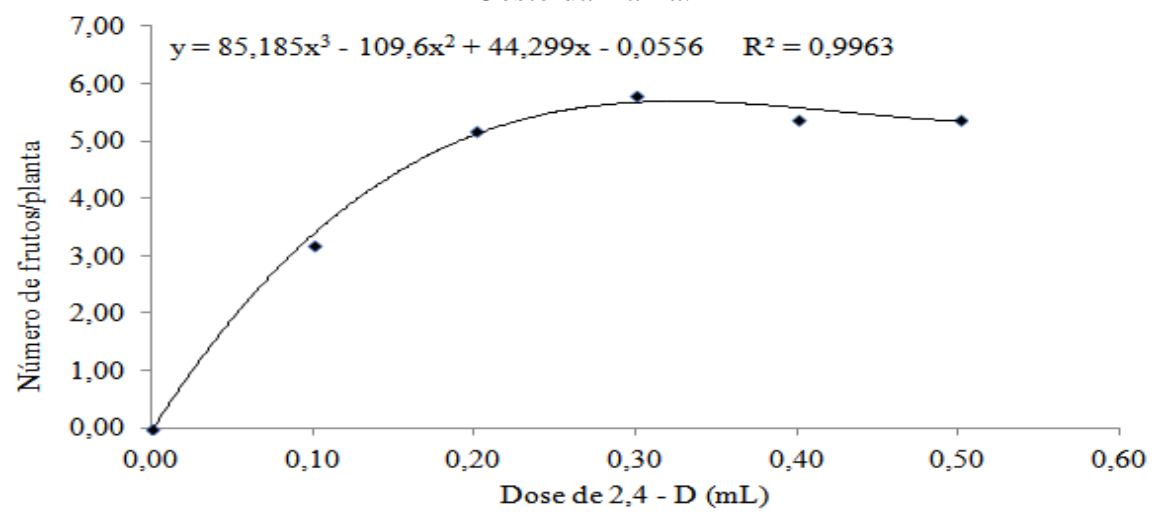

De acordo com a figura 1 observou-se que utilizando a dosagem do tratamento T1 $(0,0$ $[108]$ 
$\mathrm{mL}$ de 2,4 - D) não foi obtido nenhum fruto, no entanto, a partir do tratamento $\mathrm{T} 2(0,1 \mathrm{~mL})$ foi possível verificar o aumento no número de frutos, porém o tratamento T2 proporcionou uma pequena quantidade, com três frutos por planta, diferentemente dos tratamentos T3 $(0,2$ $\mathrm{mL})$ à T6 $(0,5 \mathrm{~mL})$ que apresentou cerca de cinco. Resultados semelhantes foram obtidos por Pasqualetto et al. (2001) quanto ao número de frutos por planta, houve tendência de aumento de valores à medida que a dose de 2,4-D foi sendo elevada.

Portanto, de acordo com a equação do gráfico de regressão foi possível obter a melhor dose para frutos por plantas, sendo o ponto máximo de eficiência técnica a dose de $0,34 \mathrm{~mL}$ de 2,4 - D, sendo assim, doses superiores provocaram decréscimo na taxa de frutos. Dessa forma, pode-se concluir que para próximos experimentos testando esta dose poderá possibilitar uma quantidade de 5,68 frutos por planta.

Figura 2: Peso médio de frutos da abóbora híbrida Tetsukabuto, em função de doses de 2,4-D, na região Oeste da Bahia.

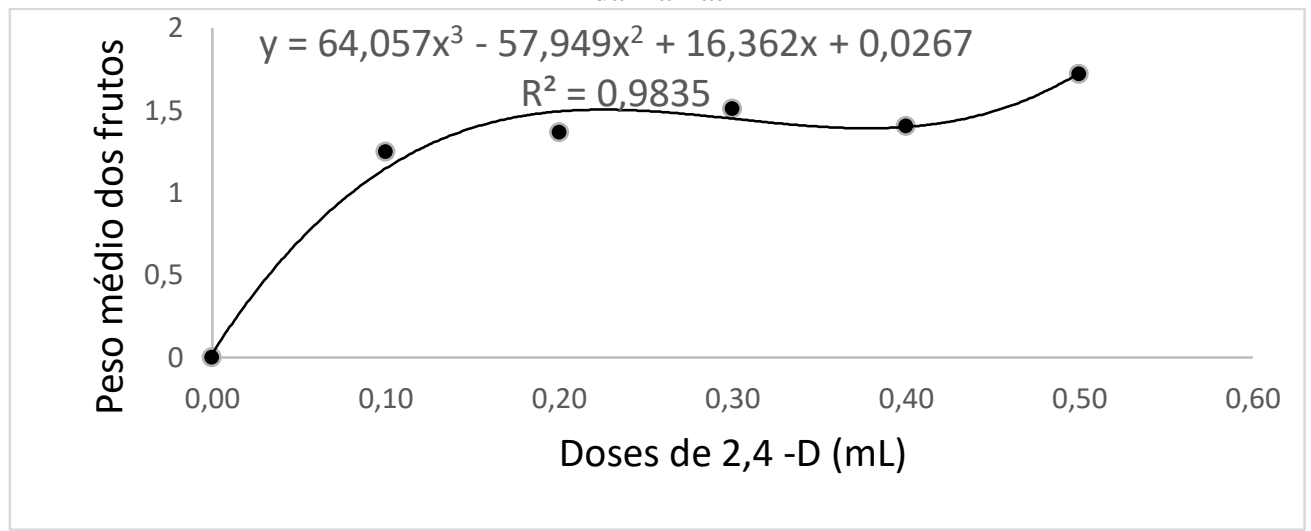

Para figura 2, verificou-se que com a aplicação do fitorregulador, os pesos médios dos frutos variavam entre 1,20 a $1,7 \mathrm{~kg}$, no qual no presente trabalho não mostrou-se viável sendo valores inferiores apresentados por Amaro et al. (2014), o peso médio ideal para frutos de Tetsukabuto, é aproximadamente de 2,0 a 3,0 kg. Tal fato pode ter ocorrido devido a um período de estresse hídrico o qual a cultura passou durante a fase de frutificação. As fases de frutificação até a maturação dos frutos são as que apresentam maior exigência hídrica (AMARO,2014). Estresses nessa fase comprometem significativamente o enchimento dos frutos.

De acordo com a equação do gráfico de regressão foi possível obter as melhores doses para peso dos frutos, onde observou-se que a medida que foi aumentando as doses de 2,4 - D também elevou-se o peso. As doses de 0,48 a 0,50 $\mathrm{mL}$ foram as que apresentaram maiores valores referente ao peso médio dos frutos, podendo chegar a $1,72 \mathrm{~kg}$. Diferente dos resultados obtidos por Nomura et al. (2019) quanto ao peso dos frutos, houve aumento de valores à medida que a dose de 2,4-D foi sendo elevada, até 141,5 mgL-1. Esse resultado 
demonstrou que esta dose estimulou a produção de frutos mais pesados, com mais de 1,08 kg de peso. A partir desta dosagem, há uma diminuição progressiva do peso dos frutos.

\section{CONCLUSÕES}

De acordo com as doses analisadas, a aplicação do regulador de crescimento nas flores femininas da abobora hibrida Tetsukabuto promoveu um desempenho satisfatórios das suas características agronômicas, descartando o plantio de culturas polinizadoras (abóbora ou moranga), possibilitando o aproveitamento de toda área com o cultivo somente do híbrido Tetsukabuto. Dessa forma o produtor, ao adotar essa pratica na região do Oeste da Bahia, pode utilizar qualquer dose a partir de 0,3 a $0,5 \mathrm{~mL}$ de 2,4-D, já que apresentaram resultados superiores as doses 0,$0 ; 0,1$ e $0,2 \mathrm{~mL}$, sendo comprovados pela análise de regressão.

\section{REFERENCIAS}

AMARO, G. B.; PINHEIRO, J. B.; LOPES, J. F.; CARVALHO, A. D. F de C.; MICHEREFF FILHO, M.; VILELA, N. J. Recomendações técnicas para o cultivo de abóbora híbrida do tipo japonesa. Circular técnica, EMBRAPA. Brasília, DF. 2014.

CARMO GA; OLIVEIRA FRA; MEDEIROS JF; OLIVEIRA FA; CAMPOS MS; FREITAS DC. 2011. Teores foliares, acúmulo e partição de macronutrientes na cultura da abóbora irrigada com água salina. Revista Brasileira de Engenharia Agrícola e Ambiental 15: 512 518.

KRISHNAMOORTHY, H.N. Plant growth substances. New Delhi: McGraw-Hill, 1981. p. 214

NOMURA, M. et al. Produção de frutos partenocárpicos de abóbora híbrida "tetsukabuto" sob aplicação de 2,4-D. Bagé-RS. Revista Científica Rural, volume 21, n², 2019. Disponível em: <http://revista.urcamp.tche.br/index.php/RCR/article/view/2729>. Acesso em: 24 de set. 2019.

PASQUALETTO, A. et al. Produção de frutos de abóbora híbrida pela aplicação de 2,4-D nas flores. Goiânia-Go. Pesquisa Agropecuária Tropical, 31(1):23-27, 2001.Disponível em: <https://www.revistas.ufg.br/pat/article/view/2522>. Acesso em: 24 de set. 2019.

PEREIRA, A. M.; SILVA, G. D.; ALMEIDA, R. R. P.; SILVA, A. B.; QUEIROGA, R. C. F. Frutificação de abóbora Tetsukabuto sobe aplicação de doses de 2,4-D na época seca em Pombal - PB. Revista Verde de Agroecologia e Desenvolvimento Sustentável, v. 7, n. 4, p. 38-43, 2012.

WITTWER, S.H. Vegetables. In: NICKELL, L.G. (ed). Plant growth regulating chemicals. Vol. 2. Florida: CRC Press, 1983. p. 213-231. 